\title{
The effect of front ZnO:Al surface texture and optical transparency on efficient light trapping in silicon thin-film solar cells
}

Michael Berginski, Jürgen Hüpkes, Melanie Schulte, Gunnar Schöpe, Helmut Stiebig, Bernd Rech, and Matthias Wuttig

Citation: Journal of Applied Physics 101, 074903 (2007);

View online: https://doi.org/10.1063/1.2715554

View Table of Contents: http://aip.scitation.org/toc/jap/101/7

Published by the American Institute of Physics

\section{Articles you may be interested in}

Amorphous silicon solar cell

Applied Physics Letters 28, 671 (2008); 10.1063/1.88617

Thin-film silicon solar cells with efficient periodic light trapping texture

Applied Physics Letters 91, 061116 (2007); 10.1063/1.2768882

A comprehensive review of $\mathrm{ZnO}$ materials and devices

Journal of Applied Physics 98, 041301 (2005); 10.1063/1.1992666

Efforts to improve carrier mobility in radio frequency sputtered aluminum doped zinc oxide films Journal of Applied Physics 95, 1911 (2004); 10.1063/1.1641524

$19.8 \%$ efficient "honeycomb" textured multicrystalline and $24.4 \%$ monocrystalline silicon solar cells Applied Physics Letters 73, 1991 (1998); 10.1063/1.122345

Tunable light trapping for solar cells using localized surface plasmons Journal of Applied Physics 105, 114310 (2009); 10.1063/1.3140609

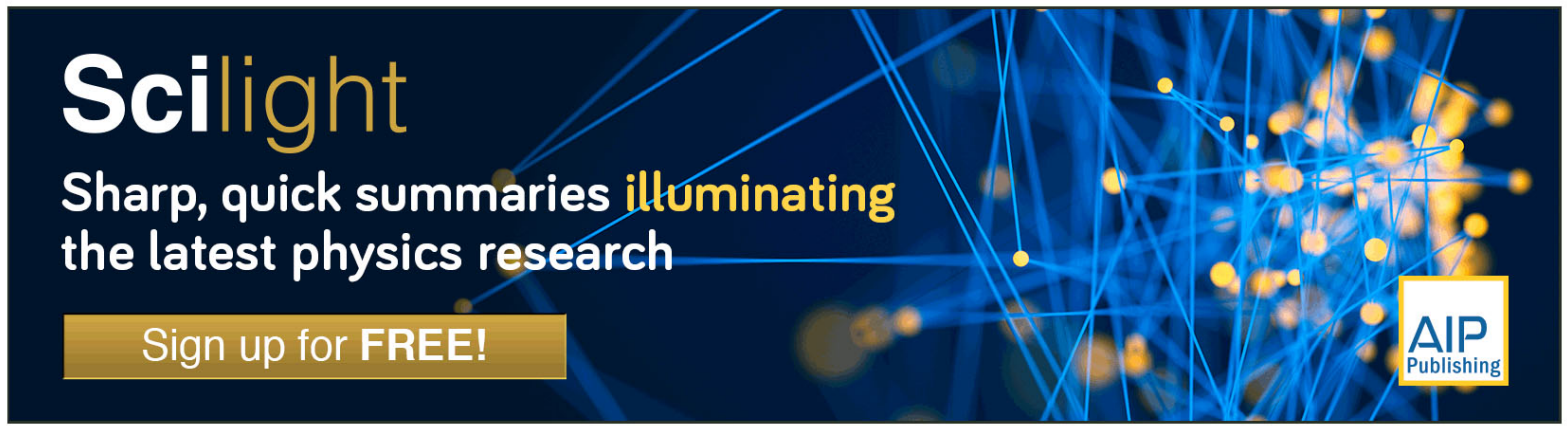




\title{
The effect of front ZnO:Al surface texture and optical transparency on efficient light trapping in silicon thin-film solar cells
}

\author{
Michael Berginski, ${ }^{a}$ Jürgen Hüpkes, Melanie Schulte, Gunnar Schöpe, Helmut Stiebig, \\ and Bernd Rech ${ }^{\text {b) }}$ \\ Institute of Photovoltaics (IPV), Forschungszentrum Jülich GmbH, D-52425 Jülich, Germany \\ Matthias Wuttig \\ Institute of Physics (IA), RWTH Aachen University, D-52056 Aachen, Germany
}

(Received 18 June 2006; accepted 27 January 2007; published online 9 April 2007)

\begin{abstract}
This study addresses the material properties of magnetron-sputtered aluminum-doped zinc oxide ( $\mathrm{ZnO}: \mathrm{Al}$ ) films and their application as front contacts in silicon thin-film solar cells. Optimized films exhibit high conductivity and transparency, as well as a surface topography with adapted light-scattering properties to induce efficient light trapping in silicon thin-film solar cells. We investigated the influence on the $\mathrm{ZnO}$ :Al properties of the amount of alumina in the target as well as the substrate temperature during sputter deposition. The alumina content in the target influences the carrier concentration leading to different conductivity and free carrier absorption in the near infrared. Additionally, a distinct influence on the film growth of the $\mathrm{ZnO}$ :Al layer was found. The latter affects the surface topography which develops during wet-chemical etching in diluted hydrochloric acid. Depending on alumina content in the target and heater temperature, three different regimes of etching behavior have been identified. Low amounts of target doping and low heater temperatures result in small and irregular features in the postetching surface topography, which does not scatter the light efficiently. At higher substrate temperatures and target doping levels, more regularly distributed craters evolve with mean opening angles between $120^{\circ}$ and $135^{\circ}$ and lateral sizes of $1-3 \mu \mathrm{m}$. These layers are very effective in light scattering. In the third regime-at very high substrate temperatures and high doping levels - the postetching surface is rather flat and almost no light scattering is observed. We applied the $\mathrm{ZnO}$ :Al films as front contacts in thin-film silicon solar cells to study their light-trapping ability. While high transparency is a prerequisite, light trapping was improved by using front contacts with a surface topography consisting of relatively uniformly dispersed craters. We have identified a low amount of target doping $(0.5-1 \mathrm{wt} \%)$ and relatively high substrate temperatures (about $350-450{ }^{\circ} \mathrm{C}$ as sputter parameters enabling short-circuit current densities as high as $26.8 \mathrm{~mA} / \mathrm{cm}^{2}$ in $\mu c-\mathrm{Si}: \mathrm{H}$ pin cells with an $i$-layer thickness of $1.9 \mu \mathrm{m}$. Limitations on further improvements of light-trapping ability are discussed in comparison with the theoretical limitations and Monte Carlo simulations presented in the literature.

(C) 2007 American Institute of Physics. [DOI: 10.1063/1.2715554]
\end{abstract}

\section{INTRODUCTION}

Various solar cell concepts can be used to utilize the photovoltaic effect for energy production. ${ }^{1-3}$ At present, the photovoltaic world market is dominated by crystalline silicon cells which accounted for nearly $95 \%$ of world photovoltaic cell and module production in $2004{ }^{4}$ The remaining share of the world photovoltaic market mainly relies on thin-film solar cell concepts. It can be assumed that several thin-film module companies already operate profitably. ${ }^{5}$ Even though thin-film solar cell production based on copper-indium diselenide (CIS), cadmium telluride (CdTe), and amorphous silicon had comparably small market shares in 2004 of about $0.25 \%, 1.1 \%$, and $3.9 \%$, respectively, these concepts are believed to be candidates for a significant production volume in the future. ${ }^{5-7}$ Thin-film solar cells might be among the very few photovoltaic techniques to reach the very low cost target

\footnotetext{
${ }^{a)}$ FAX: +49 246161 3735; electronic mail: m.berginski@fz-juelich.de

${ }^{b}$ Current address: Department of Silicon Photovoltaics (SE 1), HahnMeitner-Institut Berlin GmbH, D-12489 Berlin, Germany.
}

of $<$ US \$1/watt. Such low costs are required for photovoltaics to compete with retail electricity prices but, in the intermediate term, this can only be achieved by increasing the production capacity significantly. ${ }^{5,6,8}$ However, in the case of CIS and CdTe thin-film technologies, the use of nonabundant materials like In, Se, and Te may mean that these materials will become a dominant price factor in mass production. ${ }^{6}$

Silicon is an abundant material. Thus, silicon thin-film solar cells, due to their low costs, have a good chance of gaining a significant market share once mass production has started. There are a variety of different technical realizations for silicon thin-film solar cells. For example, silicon thin-film solar cells can be made by using one single amorphous silicon $(a-\mathrm{Si}: \mathrm{H})$ junction. However, these cells are degraded to some extent upon light soaking due to the light-induced creation of metastable defects, known as the Staebler-Wronski effect. ${ }^{9,10}$ This problem can be reduced by using a very thin $a-\mathrm{Si}: \mathrm{H}$ layer or a stack of thin layers, because in this latter case the photogenerated carriers need to move only a short distance before reaching the electrodes. ${ }^{11,12}$ A significant in- 
crease in efficiency is possible if the long wavelength response is also enhanced. Thus, another approach is to use a stack of amorphous silicon and amorphous silicon germanium $(a-\mathrm{SiGe}: \mathrm{H}){ }^{13} \mathrm{~A}$ further approach is to employ microcrystalline silicon $\mu c-\mathrm{Si}: \mathrm{H}^{14,15}$ Microcrystalline silicon solar cells are stable against light soaking or show only a very little degradation as compared to amorphous silicon solar cells. ${ }^{16,17}$ Thus, a stack consisting of a thin amorphous silicon top cell and a microcrystalline bottom cell in a so-called micromorph tandem structure offers the potential for fairly high efficiency at low cost in mass production. ${ }^{18-21}$ A stabilized efficiency of $12.0 \%$ has recently been published for a tandem structure module ${ }^{22}$ (for comparison, solar modules with sliced single crystalline and polycrystalline silicon have been reported to show efficiencies of up to $22.7 \%$ and $15.3 \%$, respectively ${ }^{23}$ ). Even though silicon thin-film modules still show rather low efficiencies compared to the other approaches, from the application point of view the annual energy production and especially the cost per unit of annual energy production is much more relevant. Focusing on these figures, thin-film amorphous silicon performs better than crystalline silicon due to a lower temperature coefficient for power loss. ${ }^{5}$ Thus, the aim of future research and development in the area of thin-film silicon solar cells is low cost annual energy production rather than merely high nominal efficiency.

Even though microcrystalline silicon solar cells or micromorph tandem cells can utilize a broader spectral range than amorphous silicon solar cells, an efficient light-trapping scheme is still essential to enhance the intrinsically low absorbance of microcrystalline silicon in the long wavelength range (wavelength $\lambda$ of above $\approx 850 \mathrm{~nm}$ ). ${ }^{24,25}$ Light trapping is achieved by combining textured transparent conductive oxide (TCO) films as front contacts and highly reflective back contacts. However, due to the multiple passage of scattered light within the solar cell device, parasitic light absorption in the photovoltaic nonactive layers (highly doped $n$ and $p$-type silicon layers, front TCO, and back reflector) is increased as well.

In the $p-i-n$ configuration the cell is illuminated through TCO coated glass. The TCO has to have counteracting properties: high conductivity to obtain low series resistance and low carrier concentration to avoid absorption losses in the red and near-infrared (NIR) wavelength range. It should be noted that in the NIR the absorbance of a single passage through a $1 \mu \mathrm{m}$ thick layer of $\mu c-\mathrm{Si}: \mathrm{H}$ is lower than that of typical TCOs. In earlier work, Agashe et al. studied the influence of the target doping concentration on the electrical, structural, and optical properties of sputter-deposited and asdeposited smooth ZnO:Al films. ${ }^{26}$ They found much lower parasitic absorptions with similar conductivity values using sputter targets with a low amount of alumina. Besides the transparency, it is crucial to develop a TCO with a suitable surface texture which scatters the light very efficiently in order to extend the effective path length within the active silicon layers. $^{27,28}$ Thus, a special design of the TCO is necessary to fulfill all these requirements. For initially smooth sputter-deposited $\mathrm{ZnO}$ :Al films a surface texture is realized by postdeposition wet-chemical etching. ${ }^{29,30}$ Kluth et al. re- lated the influence of pressure and substrate temperature during radio frequency (rf) sputter deposition of $\mathrm{ZnO}: \mathrm{Al}$ at a fixed alumina content of $2 \mathrm{wt} \%$ in the sputter target to structural properties and postetching surface topography in a modified Thornton model. ${ }^{30}$ They showed that, depending on sputter parameters, craterlike surface topography with typical lateral length scales of $1-2 \mu \mathrm{m}$ and depths of about 200-400 nm develops in a self-organized fashion. This etching behavior is affected very sensitively by structural $\mathrm{ZnO}: \mathrm{Al}$ properties. The film structure can be controlled by the deposition parameters, but there are a number of hidden parameters that are not yet fully understood. ${ }^{31}$ For example, Hüpkes et al. and Kluth et al. showed that the amount of oxygen added to the process gas strongly influences film properties. $^{32,33}$ Another of these unknown influence factors might be the target alumina concentration (TAC).

In the present study, we extend the modified Thornton model by introducing the alumina content in the target as an influential parameter for varying the etching behavior and thus surface topography for light scattering. This knowledge is essential for developing surface-textured $\mathrm{ZnO}$ : $\mathrm{Al}$ films for efficient light trapping based on the improved optical and electrical properties of as-deposited smooth thin films found by Agashe et al. We briefly show structural, optical, and electrical properties supporting the results of Agashe et al. with additional data. Aiming to design an optimized front TCO for thin-film solar cells, we study the growth of the $\mathrm{ZnO}: \mathrm{Al}$ films and characterize the surface texture of the films after etching in $\mathrm{HCl}$. Finally, optimized films are applied in solar cells and calculations of an effective light pass enhancement factor are presented. We focus on single junction microcrystalline silicon thin-film solar cells in order to study the light-trapping ability of the front contacts, particularly in the long wavelength range. Optimized $\mathrm{ZnO}$ :Al films can later be applied in stacked multijunction cells with amorphous and microcrystalline silicon absorber layers. Finally, in order to quantify the success of the experimental achievements, we compare the light-trapping ability in our cells with simulations of nearly idealized conditions and statistical mechanically derived general limitations.

\section{EXPERIMENTAL DETAILS}

ZnO:Al films were prepared on Corning 1737 glass by rf magnetron sputtering from ceramic targets in static or dynamic modes. The amount of doping was varied by using $\mathrm{ZnO}: \mathrm{Al}_{2} \mathrm{O}_{3}$ targets with $0.2,0.5$, 1 , or 2 wt $\%$ of $\mathrm{Al}_{2} \mathrm{O}_{3}$. The concentration of $\mathrm{Al}_{2} \mathrm{O}_{3}$ in the target is henceforth referred to as TAC. At constant deposition pressure of $0.3 \mathrm{~Pa}$ (in the case of $0.2,0.5$, and 2 wt $\%$ TAC) and $0.1 \mathrm{~Pa}$ (in the case of $1 \mathrm{wt} \% \mathrm{TAC}$ ) the substrate temperature was varied in a range of $60-490{ }^{\circ} \mathrm{C}$. Substrate temperature was calibrated by a thermal sensor and was controlled by the heater temperature. Film characterization was done by a four-point probe, room temperature Hall effect measurements at room temperature and by $\mathrm{x}$-ray diffraction analysis. Optical transmittance and reflectance of smooth films, as well as the total and diffuse transmission on texture-etched films (in order to calculate the haze), were measured in air with a dual beam spectrometer. 
For textured $\mathrm{ZnO}$ :Al films, $\mathrm{CH}_{2} \mathrm{I}_{2}$ was applied in transmittance and reflectance measurements as an index-matching fluid to avoid systematic measurement errors due to light scattering of the rough films. ${ }^{34}$ By wet-chemical etching in diluted hydrochloric acid $(0.5 \% \mathrm{HCl})$, the approximately $800 \mathrm{~nm}$ thick initially smooth films (rms roughness of about $15 \mathrm{~nm}$ ) were transformed into surface-textured films with a typical rms roughness of more than $100 \mathrm{~nm}$. The surface topography and characteristic feature sizes were studied by scanning electron microscopy (SEM) and atomic force microscopy (AFM). The surface topographies determined by atomic force microscopy were statistically analyzed. However, the most effective way to characterize the light-trapping ability of a specific TCO film is by applying it in solar cells. For this purpose, we deposited $\mu c-\mathrm{Si}: \mathrm{H}$ single junction solar cells by plasma-enhanced chemical vapor deposition (PECVD) at $13.56 \mathrm{MHz}$ excitation frequency in a 30 $\times 30 \mathrm{~cm}^{2}$ reactor. ${ }^{35}$ Double layers of sputter-deposited $\mathrm{ZnO}: \mathrm{Al}(80 \mathrm{~nm})$ and thermally evaporated silver $(700 \mathrm{~nm})$ served as the back reflector and rear side contact. Details of cell preparation are given elsewhere. ${ }^{28}$ Solar cell characteristics were measured using a sun simulator (Wacom-WXS140S-Super) under standard test conditions (AM 1.5, $100 \mathrm{~mW} / \mathrm{cm}^{2}$ at $25^{\circ} \mathrm{C}$ ). The external quantum efficiency (QE) of some solar cells was measured by differential spectral response at zero bias. From the QE the short-circuit current density, which corresponds to the maximum current density generated by the solar cell, was calculated employing the AM 1.5 solar spectrum with an illumination density of $100 \mathrm{~mW} / \mathrm{cm}^{2}$ with the corresponding photon flux. In the following, the short-circuit current density calculated in this way is referred to as the cell current density.

\section{RESULTS}

\section{A. Structural, electrical, and optical ZnO:Al film properties}

As is typical of magnetron-sputtered $\mathrm{ZnO}: \mathrm{Al}$ films, ${ }^{36}$ all the films in this study exhibit a strong texture with the $c$ axis predominantly orientated parallel to the substrate normal. Therefore, the x-ray diffraction spectra in Bragg-Brentano geometry exhibit strong peaks corresponding to the [001] direction. All other peak intensities are at least a factor of one hundred lower than that of the (002) peak. Figure 1 shows the peak position and full width at half maximum (FWHM) of the (002) peak as function of substrate temperature $T$. While the peak position shifts towards higher angles with increasing substrate temperature in the case of low TAC, the trend is opposite for the target with $2 \mathrm{wt} \%$ TAC. A shift of peak position towards lower angles usually indicates compressive stress, which is attributed to high-energy ion bombardment during growth by sputter deposition. The FWHM of the (002) peak decreases with substrate temperature for low doping concentration and, once again, only in case of 2 wt \% TAC does the FWHM strongly increase at high substrate temperatures. This means that the number of coherently scattering crystal planes decreases. This either corresponds to crystallite size or is limited by microstress within a single crystallite.

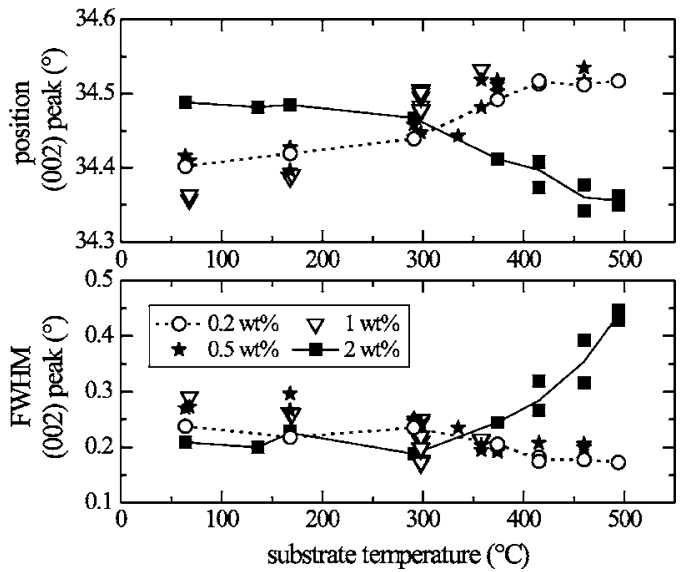

FIG. 1. X-ray diffraction spectra in Bragg-Brentano geometry were evaluated with respect to the position (upper graph) and the full width at half maximum (lower graph) of the dominant (002) peak. The data points at, e.g., $300{ }^{\circ} \mathrm{C}$ and $1 \mathrm{wt} \%$ TAC were measured for nominally identical $\mathrm{ZnO}: \mathrm{Al}$ films. Scattering of data points is caused by statistical experimental errors.

The TAC influences the amount of $\mathrm{Al}$ doping and in this way determines the number of free carriers in the $\mathrm{ZnO}: \mathrm{Al}$ films. ${ }^{37}$ Figure 2 shows the carrier concentration $N$ and mobility $\mu$ as a function of substrate temperature $T$. While in the case of 0.5 and $1 \mathrm{wt} \% \mathrm{TAC}$, the carrier concentration tends to be maximal at substrate temperatures of $300-350{ }^{\circ} \mathrm{C}$; films sputtered with a TAC of 0.2 and 2 wt $\%$ gradually change their carrier concentration. Increasing the substrate temperature during sputtering leads to a higher $N$ in case of $0.2 \mathrm{wt} \%$ TAC and to a lower $N$ in case of $2 \mathrm{wt} \%$ TAC. The carrier mobility seems to be maximal at a certain substrate temperature which increases when TAC is reduced. Carrier mobility was further improved by optimized deposition conditions compared to the data of Agashe et al. ${ }^{26}$

Figure 3 shows transmission and absorption spectra of $\mathrm{ZnO}: \mathrm{Al}$ films sputtered at a fixed substrate temperature of $375{ }^{\circ} \mathrm{C}$ using $0.2,0.5$, and $2 \mathrm{wt} \%$ TAC. The absorption was calculated using transmission and reflection spectra. Increasing the TAC mainly increases the absorption of NIR light and the carrier concentration $N$ (see inset, values are given in $10^{20} \mathrm{~cm}^{-3}$ ) in the films. Simultaneously, the resistivity $\rho$ (see

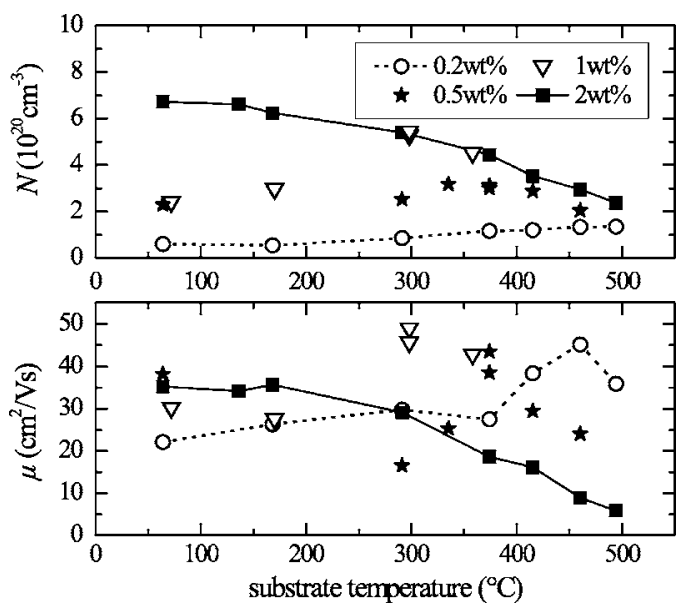

FIG. 2. Carrier concentration $N$ (top graph) and carrier mobility $\mu$ (bottom graph) measured using Hall measurements in van der Pauw geometry. 


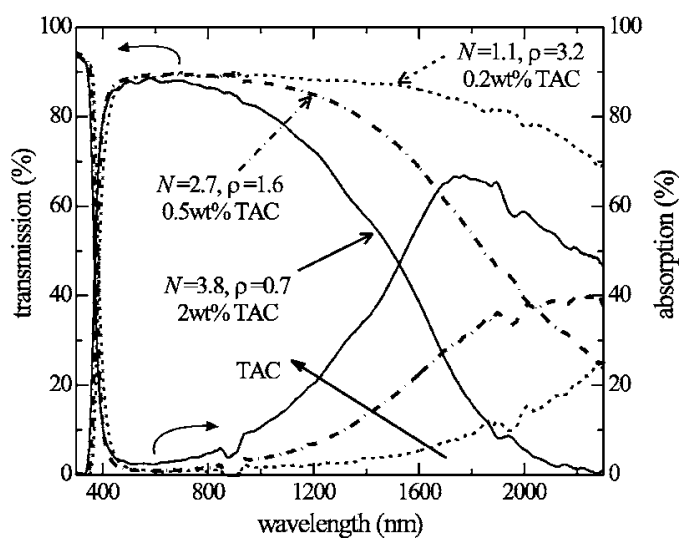

FIG. 3. Transmission (left axis) and absorption (right axis) spectra of surface-textured front contacts sputtered at substrate temperature of $375{ }^{\circ} \mathrm{C}$ using $\mathrm{ZnO}: \mathrm{Al}_{2} \mathrm{O}_{3}$ targets with $0.2,0.5$, and $2 \mathrm{wt} \% \mathrm{TAC}$, respectively. The optical data can only be considered for $\lambda>400 \mathrm{~nm}$, as $\mathrm{CH}_{2} \mathrm{I}_{2}$ is strongly absorbing for smaller wavelengths. The discontinuity in the data around $\lambda$ $=900 \mathrm{~nm}$ is due to an artifact of the measurement system.

inset, values are given in $10^{-3} \Omega \mathrm{cm}$ ) decreases. In addition, the fundamental absorption band edge is shifted to smaller wavelengths (Burstein-Moss shift ${ }^{38,39}$ ). Note that this effect is partially masked by the index-matching fluid applied during measurements. For high doping levels, the parasitic free carrier absorption mechanism significantly reduces the transmission in the active range of the solar cells (up to about $1100 \mathrm{~nm}$ ). A compromise has to be found between transmission and conductivity in order to prepare optimized $\mathrm{ZnO}: \mathrm{Al}$ front contacts for solar cells. However, even though high transmission and low resistance are prerequisites, earlier work has shown that surface roughness, feature size, and shape are key parameters for highly efficient light trapping. ${ }^{27,40}$ Thus, we concentrate in the following section on $\mathrm{ZnO}: \mathrm{Al}$ surface structure observed after etching.

\section{B. Postetching surface topography}

After deposition the initially smooth films were surface textured by wet-chemical etching in diluted hydrochloric acid. The etching time was adapted in such a way that approximately $150 \mathrm{~nm}$ of the film thickness was removed, leading to a final thickness of about $650 \mathrm{~nm}$. Depending on the TAC and substrate temperature, three clearly different postetching surface structures appear. One specimen of each type is shown in Fig. 4(a). The first type (denoted by I in Fig. 4) typically comprises a very rough surface with lateral feature sizes of about $300 \mathrm{~nm}$ and with rather steep edges. For the second type (II), the surface is almost uniformly covered by large craters with diameters ranging from 1 to $3 \mu \mathrm{m}$ and depths of about $150-400 \mathrm{~nm}$. The third type (III) develops a comparatively flat surface with plenty of shallow craters with depths of up to about $100 \mathrm{~nm}$ and a few large craters with lateral diameters of up to $3 \mu \mathrm{m}$ and depths of up to $700 \mathrm{~nm}$ (limited by film thickness) in the case of the large craters. The postetching topography types I, II, and III are found in different growth regimes, as illustrated in Fig. 4(b). With increasing $T$ the growth changes from types I and II to III. The transition temperature for changing the regimes shifts to higher values if TAC is reduced. At the same time the $T$
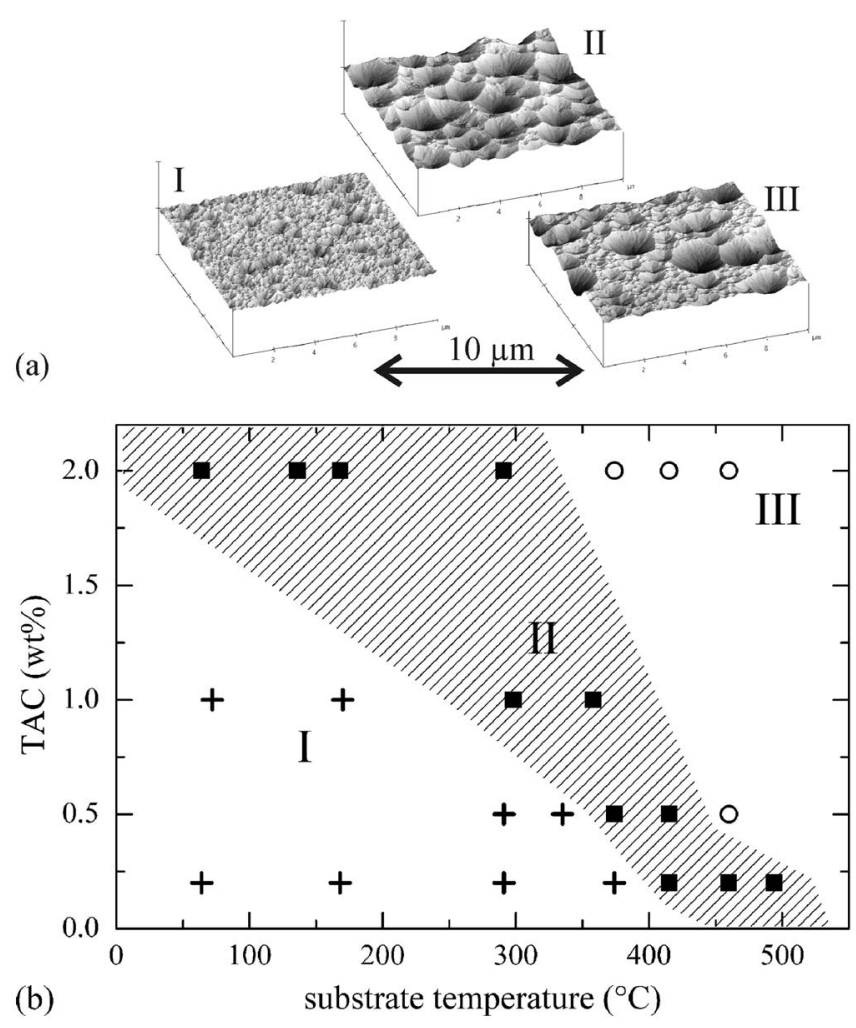

FIG. 4. (a) AFM $10 \times 10 \mu \mathrm{m}^{2}$ measurements (top) and (b) schematic distribution of etching behavior types in a matrix of parameter substrate temperatures and TAC (crosses: type I, squares: type II, and circles: type III). The parameter space where we expect to find type II films is hatched.

range for type II films becomes narrow. The transition between the regimes is not sharp. In order to incorporate these findings into the modified Thornton model introduced by Kluth et al. ${ }^{30}$ the substrate temperature axis has to be rescaled taking TAC into account since increasing substrate temperature and increasing TAC both have similar effects on changing growth conditions.

Four examples of type II topographies are illustrated by SEM micrographs in Fig. 5. Over a broad range of TAC and substrate temperature a postetching surface topography can
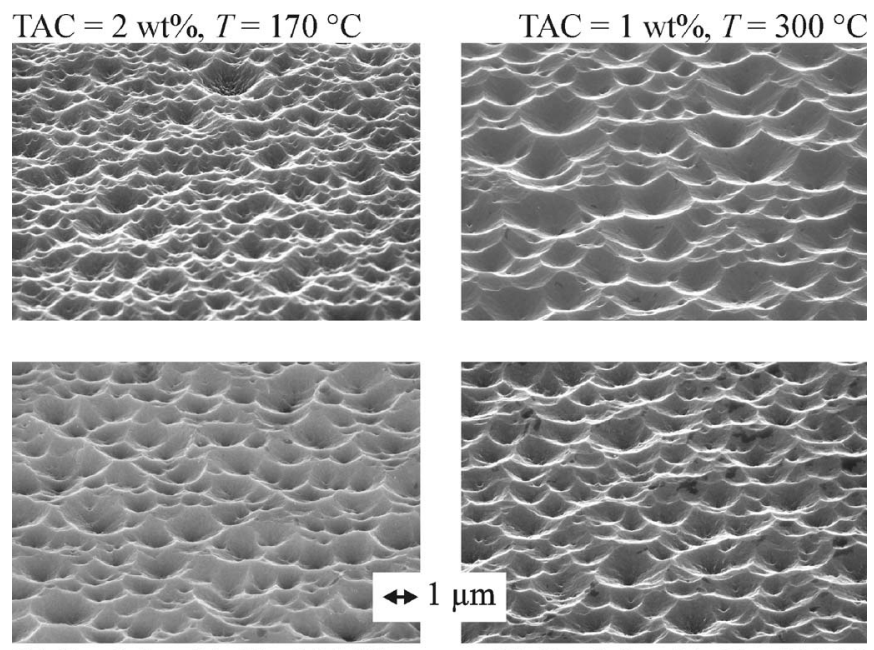

$\mathrm{TAC}=0.5 \mathrm{wt} \%, T=375^{\circ} \mathrm{C}$

$\mathrm{TAC}=0.2 \mathrm{wt} \%, T=460{ }^{\circ} \mathrm{C}$

FIG. 5. SEM micrographs of texture-etched $\mathrm{ZnO}: \mathrm{Al}$ films of surface topography type II. 


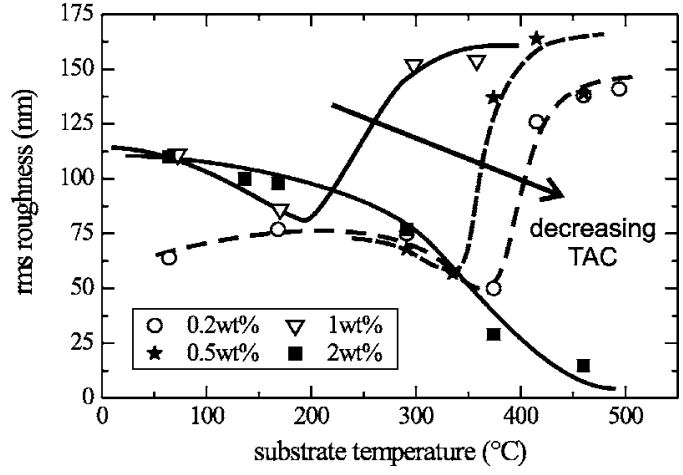

FIG. 6. Calculated rms roughness data points using AFM measurements of texture-etched $\mathrm{ZnO}$ :Al films with different TACs. Guide-to-the-eye lines are additionally drawn.

be achieved that is uniformly covered by similarly sized craters. Changing the TAC has only a minor influence on the crater size distribution if the substrate temperature is adjusted.

AFM measurements were used to determine the rms roughness values that are given as a function of substrate temperature in Fig. 6. In the case of $0.2,0.5$, and $1 \mathrm{wt} \%$ $\mathrm{TAC}$, the rms roughness increases steeply beyond a certain substrate temperature. This transition temperature increases with decreasing TAC. Films sputtered from 2 wt \% TAC show decreasing rms roughness with increasing $T$. Correlating this behavior to the postetching surface topography types indicates that surface topographies of regime II typically have the highest rms roughness of up to $160 \mathrm{~nm}$. In general, with surface topography changing from type I or III to type II the rms values increase significantly.

Besides calculating rms roughness, we analyzed the AFM data with a computer program developed by Stiebig and Schulte (for details, see Ref. 41). The computer program defines-by means of each set of three neighboring AFM data points - a corresponding plane. The inclination of these planes was calculated with respect to the film normal. The angles can be expressed in terms of crater opening angles $\gamma$, which correspond to twice the inclination angle to the substrate normal. Figure 7 shows a histogram of opening angles for two examples of types I and II surface topography. By

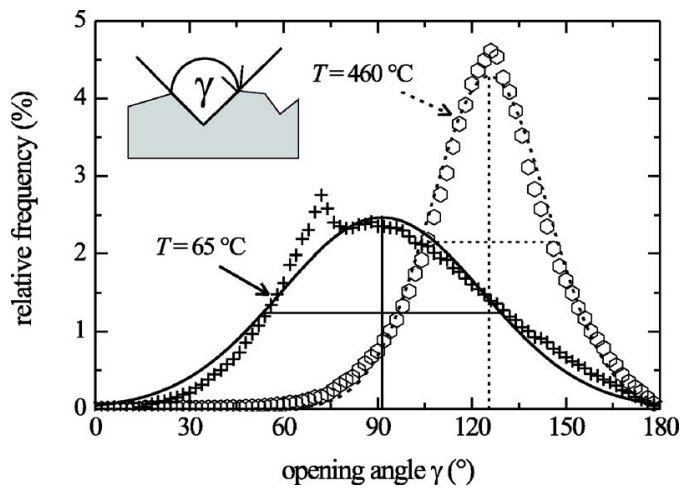

FIG. 7. Relative frequency distribution of crater opening angles (data points) and Gaussian fit (lines) of two films sputtered using a TAC of $0.2 \mathrm{wt} \%$ and different substrate temperatures. The center of the Gaussian fit and its FWHM are indicated.

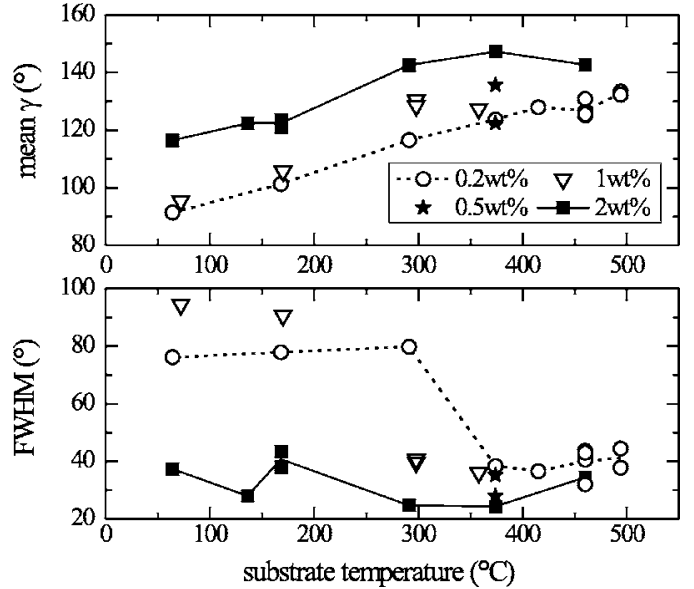

FIG. 8. Mean values (top) and FWHM (bottom) of the crater opening angle $\gamma$ distributions determined by Gaussian fit of the frequency distribution functions of the AFM data (compare Fig. 7).

means of a Gaussian fit, the mean crater opening angles and corresponding FWHM values were obtained (see Fig. 8). While the histogram of the film with surface topography type I (sputtered at heater temperature of $65^{\circ} \mathrm{C}$ ) is centered around angles of approximately $90^{\circ}$ with a broad variation, the frequency distribution of the film of type II (sputtered at $460{ }^{\circ} \mathrm{C}$ ) is centered around significantly higher angles and is comparatively sharp. Comparing all the data (see Figs. 4 and 8 ), we find a mean $\gamma$ in the range of $120^{\circ}-135^{\circ}$ for type II topographies. The FWHM of the crater opening angle distributions is between $20^{\circ}$ and $45^{\circ}$. Type I topographies (TAC of 0.2 and $1 \mathrm{wt} \%$ ) show a considerably larger FWHM, indicating that in this case there is much more deviation in surface topography feature dimensions.

\section{Light scattering and solar cell application}

In order to further study the light scattering of the texture-etched films, the haze of these layers was determined (Fig. 9 shows haze values at a fixed wavelength of $\lambda$ $=1 \mu \mathrm{m})$. While the analysis of the AFM topography has shown a continuous shift in crater opening angle, the haze value increases perceptibly when substrate temperature exceeds a critical value. This temperature coincides with the change in topography type from I to II. Again, the layers

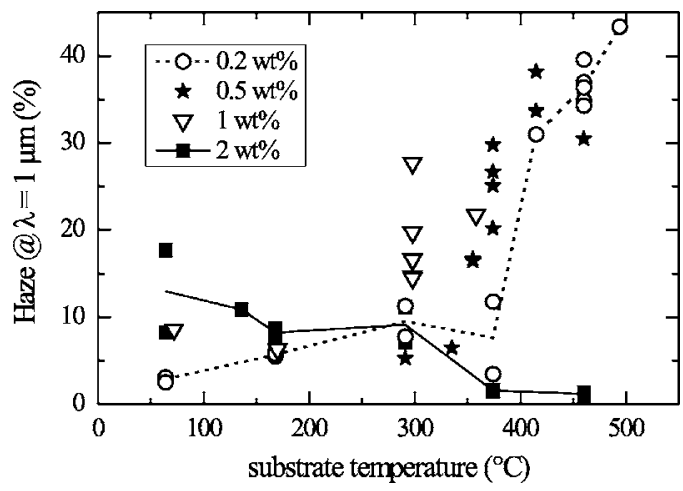

FIG. 9. Haze values at wavelength $\lambda=1 \mu \mathrm{m}$. Type II topographies tend to have the highest haze values. Films sputtered using 2 wt \% TAC in general have lower haze values. 


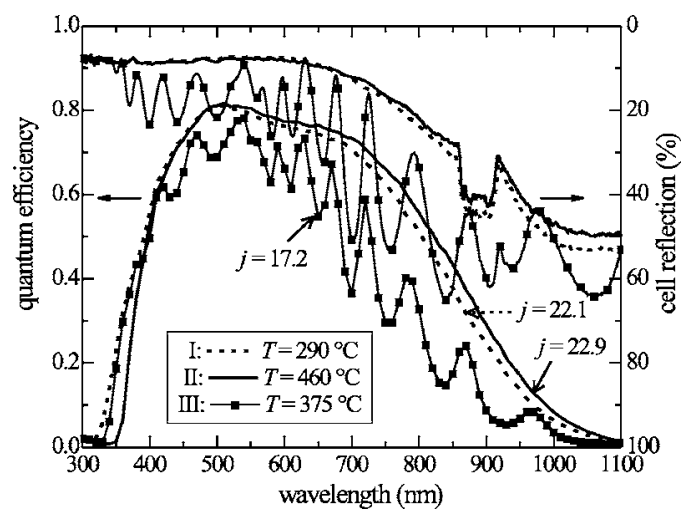

FIG. 10. Quantum efficiency (left axis) and cell reflection (right axis) of a series of $\mu c-\mathrm{Si}: \mathrm{H}$ solar cells with intrinsic silicon layer thickness of about $1 \mu \mathrm{m}$. Front TCOs of surface topography types I, II (both with $0.2 \mathrm{wt} \%$ TAC), and III (2 wt \% TAC) are compared. Cell current densities were calculated using the solar AM 1.5 spectrum (see inset, values are given in $\mathrm{mA} / \mathrm{cm}^{2}$ ). The cell with front contact of type I was measured with an applied bias of $-0.5 \mathrm{~V}$ due to poor electrical properties of the corresponding front TCO. The discontinuity in the data of the cell reflection around $\lambda$ $=900 \mathrm{~nm}$ is due to an artifact of the measurement system. Note the different direction of the right axis. In this case, the reflection curves can be interpreted as total cell absorption.

sputtered using a TAC of $2 \mathrm{wt} \%$ deviate in their behavior: the haze decreased significantly for high substrate temperatures. In the investigated temperature range, we cover a topography type change from II to III for TAC of $2 \mathrm{wt} \%$ corresponding to a decrease in haze values.

In order to study the light-trapping ability in thin-film solar cells, we applied the $\mathrm{ZnO}: \mathrm{Al}$ films in $\mu c-\mathrm{Si}: \mathrm{H}$ single junction cells with intrinsic $\mu c-\mathrm{Si}: \mathrm{H}$ layer absorber thickness of about $1 \mu \mathrm{m}$. Figure 10 shows the QE data and cell reflections of solar cells prepared on $\mathrm{ZnO}: \mathrm{Al}$ films with different surface topography types. In the case of type I topography (TAC of $0.2 \mathrm{wt} \%, T=290{ }^{\circ} \mathrm{C}$ ), a certain degree of light trapping is already apparent because of the roughness of these layers. Due to the poor electrical quality of the $\mathrm{ZnO}: \mathrm{Al}$ film, the quantum efficiency of the corresponding cell had to be measured with applied negative bias in order to collect all the carriers generated. The cell current density of this cell was $22.1 \mathrm{~mA} / \mathrm{cm}^{2}$. The electrical performance and lighttrapping ability was improved by using type II front contacts (TAC of $0.2 \mathrm{wt} \%, T=460{ }^{\circ} \mathrm{C}$ ), consisting of relatively uniformly dispersed craters. In this case, the cell current density reached $22.9 \mathrm{~mA} / \mathrm{cm}^{2}$ due to an improved $\mathrm{QE}$ in the red and NIR wavelength ranges. The gain in efficiency is considerable due to the much better electrical properties of the $\mathrm{ZnO}$ :Al leading to a high fill factor and open circuit voltage. A front TCO with type III topography (TAC of $2 \mathrm{wt} \%, T$ $=375{ }^{\circ} \mathrm{C}$ ) is noticeably less successful in trapping the light within the cell. It mainly consists of flat regions without significant light scattering, leading to a low QE with a cell current density of only $17.2 \mathrm{~mA} / \mathrm{cm}^{2}$ and interference fringes similar to cells prepared on smooth front contacts. ${ }^{28}$

Figure 11 shows a summary of cell current densities as a function of TAC and substrate temperature during sputtering. These results can be partly explained by employing the rms roughness and haze data (see Fig. 6) and the assumption that higher roughness implies better light trapping. It should be

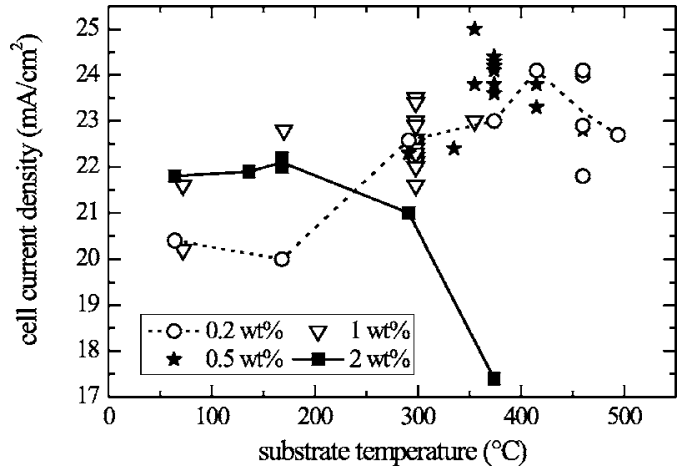

FIG. 11. Current densities calculated using measured quantum efficiencies of $\mu c-\mathrm{Si}: \mathrm{H}$ pin cells ( $i$-layer thickness of $1 \mu \mathrm{m}$ ). In the case of very highOhmic front contacts the cells were measured with a negative bias of up to $-0.5 \mathrm{~V}$ in order to be able to collect all the carriers generated.

noted that this model is too simple to explain the lighttrapping ability in all details. A detailed discussion of the relation of surface topography and light trapping can be found in the literature. ${ }^{40,41}$ In the case of $2 \mathrm{wt} \%$ TAC, the topography type changes from regime II to regime III by increasing the substrate temperature from 300 to $400{ }^{\circ} \mathrm{C}$. Due to the poor light-trapping ability of type III films, the cell current density drops steeply towards the level of cells fabricated on nontextured front contacts (cf. data of Rech $e t$ al.: $\left.15.6 \mathrm{~mA} / \mathrm{cm}^{2}\right){ }^{28}$

In the case of $0.2,0.5$, and $1 \mathrm{wt} \% \mathrm{TAC}$, we mainly studied topography types I and II. There is a rather steep increase in roughness changing the surface topography regime. The cell current densities observed for type II front contacts are significantly higher than $21 \mathrm{~mA} / \mathrm{cm}^{2}$. Nevertheless, the highest currents are found for type II films and are found at high substrate temperatures with a rather low TAC.

To further study the necessity of TCO transparency for optical cell efficiency we deposited a series of $\mu c-\mathrm{Si}: \mathrm{H}$ solar cells with varying silicon thicknesses of $0.5,1$, and $1.9 \mu \mathrm{m}$ on type II front contacts with TAC of $0.5 \mathrm{wt} \%$ ( $T$ $\left.=375{ }^{\circ} \mathrm{C}\right)$ and $\mathrm{TAC}$ of $1 \mathrm{wt} \%\left(T=300{ }^{\circ} \mathrm{C}\right)$. Figure 12 shows the quantum efficiencies of these cells as well as the cell reflections of the two cells with a $1.9 \mu \mathrm{m} \mu c-\mathrm{Si}: \mathrm{H}$ layer. Reducing the parasitic absorption in the front TCO increases the quantum efficiency and the cell reflection and thus shortens the gap between quantum efficiency and $1-R$. With increasing thickness of the intrinsic silicon layer the influence of parasitic losses in the front TCO, in the doped silicon layers, and at the back reflector is reduced since the absorbance of the intrinsic silicon layer increases relative to the parasitic absorption. A cell current density of up to $26.8 \mathrm{~mA} / \mathrm{cm}^{2}$ has been achieved experimentally in the case of an intrinsic silicon layer thickness of $1.9 \mu \mathrm{m}$ (see quantum efficiency in Fig. 12).

The QE data shown in Fig. 12 were used to estimate an effective light pass enhancement factor $f$. In order to consider the different TCO absorptions $A_{\text {TCO }}$ during the first pass before entering he $\mu c-\mathrm{Si}: \mathrm{H}, \mathrm{QE}$ is normalized to: $\mathrm{QE}_{\text {rescaled }}$ $=\mathrm{QE} /\left(1-A_{\mathrm{TCO}}\right)$. The absorption $A_{\mathrm{TCO}}$ was calculated from the transmission and reflection (see Fig. 3). Using an absorber layer thickness $d$ and absorption coefficient $\alpha$ of 


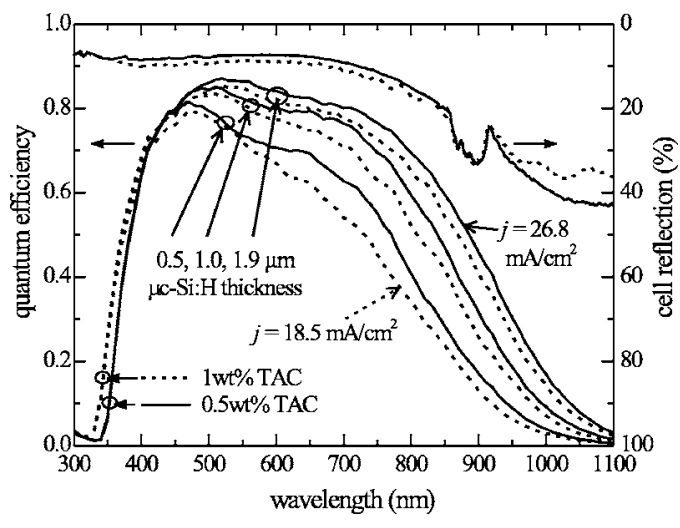

FIG. 12. Quantum efficiencies (left axis) of a series of $\mu c-\mathrm{Si}: \mathrm{H}$ solar cells with varying silicon layer thickness: $0.5,1$, and $1.9 \mu \mathrm{m}$. The cell current densities in $\mathrm{mA} / \mathrm{cm}^{2}$ are 18.5 (thinnest silicon layer), 23.0, and 25.8 (thickest silicon layer) in the case of $1 \mathrm{wt} \%$ TAC (dashed lines), and 20.2 (thinnest), 24.3, and 26.8 (thickest) in the case of $0.5 \mathrm{wt} \%$ TAC (solid lines), respectively. The cell reflection of the two cells with $1.9 \mu \mathrm{m}$ intrinsic $\mu c-\mathrm{Si}: \mathrm{H}$ is shown on the right axis. The discontinuity in the data of the cell reflection around $\lambda=900 \mathrm{~nm}$ is due to an artifact of the measurement system.

$\mu c$-Si:H measured by photothermal deflection spectroscopy, ${ }^{42}$ the enhancement factor $f$ is calculated by

$$
\mathrm{QE}_{\text {rescaled }}=1-\exp (-\alpha f d) \Leftrightarrow f=\frac{-\ln \left(1-\mathrm{QE}_{\text {rescaled }}\right)}{\alpha d} .
$$

This calculation of $f$ assumes that every absorbed photon in the intrinsic $\mu c-\mathrm{Si}: \mathrm{H}$ material generates one electron-hole pair which could be collected during the measurements. Thus, this simplification leads to an underestimation of the enhancement factor, especially since it also does not consider reduced light intensity by absorption losses in the rough $\mathrm{ZnO} / \mathrm{Ag}$ back reflector ${ }^{43,44}$ and doped silicon layers.

Figure 13 shows the $f$ values calculated from the data shown in Fig. 12. For short wavelengths the value is below unity, which simply means that light of these wavelengths is absorbed within the first few nanometers of the silicon before it reaches the back reflector. At wavelengths $\lambda>600 \mathrm{~nm}, f$ exceeds unity if light scattering enhances the path length geometrically and, additionally, if the light is trapped between the front contact and back reflector. The effective light

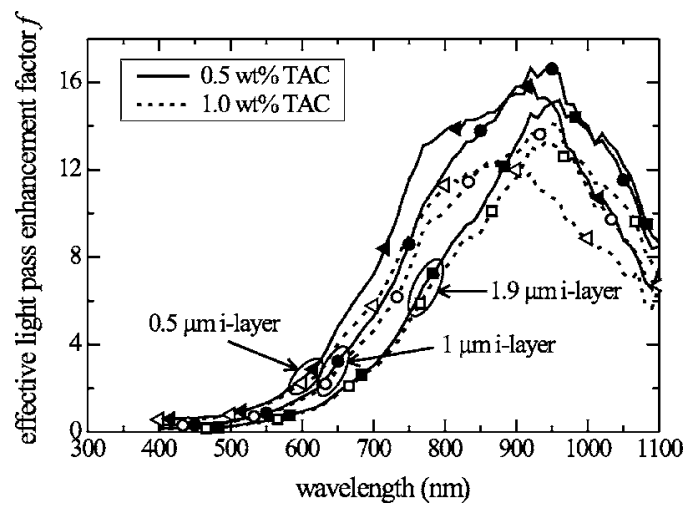

FIG. 13. Effective light pass enhancement factor $f$ calculated using quantum efficiencies from Fig. 12 and front TCO absorptions of a single pass (not shown). pass enhancement factor is maximal at wavelengths $\lambda$ $\approx 950 \mathrm{~nm}$ before it starts to decrease. The reduction in $f$ in the long wavelength part of the spectrum is very likely due to the increasing influence of additional parasitic absorption losses (e.g., at the front and back contacts) and the abovementioned underestimations. Besides this effect, the surface topographies might scatter these photons less efficiently. The enhancement factor of the cells employing the less absorbing front $\mathrm{ZnO}: \mathrm{Al}$ (solid lines and solid symbols) are significantly larger over a broad spectral region compared with the cells using $1 \mathrm{wt} \%$ TAC (dashed lines and open symbols). Both TCOs have a postetching topography type II and look very similar (compare Fig. 5). If we assume an equally efficient light scattering this estimation can give an idea of the importance of NIR transparency of the front contacts. Figure 13 shows that increasing the transparency of the front TCO results in a gain that exceeds the gain expected from a single pass through the front TCO since the QE values used for the calculation were already rescaled to compensate the absorption during the first TCO passage. Thus, the NIR absorption of the TCOs is very likely seen several times during light trapping in the cells making it important to improve the transparency of the front TCO.

\section{DISCUSSION OF RESULTS WITH RESPECT TO THEORETICAL LIMITATIONS}

\section{A. Current experimental status}

In the following, we compare the light-trapping ability in cells employing front TCO at the present experimental status with theoretical calculations and simulations. In the literature, there are many different approaches for deriving lighttrapping limits from theoretical calculations. As an upper limit, Yablonovitch and Cody ${ }^{45,46}$ derived a factor of $2 n^{2}$ for light intensity enhancement in a transparent dielectric medium with refractive index $n$. The authors claim that in the case of an absorbing medium this can lead to an absorption enhancement factor of twice the intensity enhancement factor because of angle-averaging effects, resulting altogether in a factor of $4 n^{2}$. Their statistical mechanical derivation assumes that wave optical effects can be ignored. This is mainly valid for thick films: $n d \gg \lambda / 2$. A dielectric film is irradiated from one side. While this front side is assumed to face air $\left(n_{\text {air }}=1\right)$ and to have zero reflectivity, the rear side is ideally reflective. The external irradiation field has to consist of isotropic black-body radiation and the system has to be ergodic. Yablonovitch claims ${ }^{46}$ that these last two requirements can be relaxed to the demand that the surface of the medium has to be rough enough to angularly randomize the light paths.

Tiedje et al. extended this theory by additionally considering a small amount of absorption $(\alpha d \ll 1)$ in the dielectric medium. ${ }^{47}$ Assuming radiative recombination to be the dominant recombination mechanism, they derive the absorbance $A_{\mathrm{LT}}$ (LT=light trapping) of the dielectric medium as 


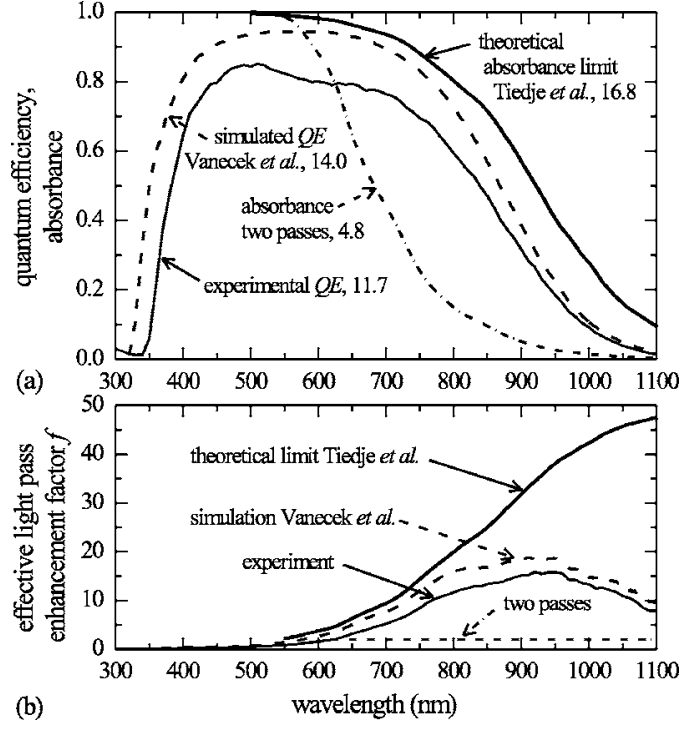

FIG. 14. (a) Comparison of measured and simulated quantum efficiency and calculated absorbance. Experimental QE data belong to a $\mu c-\mathrm{Si}: \mathrm{H}$ solar cell with silicon layer thickness of $1 \mu \mathrm{m}$ (same data as in Fig. 12, $0.5 \mathrm{wt} \%$ TAC). The cell current density was $24.3 \mathrm{~mA} / \mathrm{cm}^{2}$. For comparison, simulated quantum efficiency data by Vanecek et al. (Ref. 23) of a $1 \mu \mathrm{m}$ thick $\mu c$-Si:H cell with nearly optimal conditions are shown (dashed line). In the case of no light trapping (dotted data) and in the case of light trapping as in the model studied by Tiedje et al. (Ref. 22) [Eq. (2)], calculated absorbencies are additionally shown [both using absorption coefficient $\alpha$ (see Ref. 42) and assuming $1 \mu \mathrm{m} \mu c$-Si:H thickness]. In order to compare the lighttrapping ability, cell current densities of the spectral region of $650-1100 \mathrm{~nm}$ are calculated (values in $\mathrm{mA} / \mathrm{cm}^{2}$ are given in the graph). (b) Calculated effective light pass enhancement factor $f$ corresponding to data from Fig. 14(a): QE data without rescaling due to TCO absorption and calculated absorbances $A_{\mathrm{LT}}$ and $A_{\text {noLT }}$ were substituted in Eq. (1) for $\mathrm{QE}_{\text {rescaled }}$.

$$
A_{\mathrm{LT}}=\frac{\alpha}{\alpha+1 /\left(4 n^{2} d\right)}
$$

This absorbance can be regarded as a statistical mechanical upper limit for the quantum efficiency of solar cells since it does not include parasitic losses in other layers and since it is based on the idealized light-trapping limit of Yablonovitch et al.

Vanecek et al. studied the light trapping of real silicon thin-film solar cells and stressed the effect of small parasitic absorptions by the photovoltaically nonactive layers using Monte Carlo simulations. ${ }^{48}$ In one of their simulations they assumed nearly idealized conditions such as antireflection coatings, high transparencies of the front TCO and doped silicon layers, Lambertian light scattering, and high back contact reflectivity. Figure 14(a) shows experimental QE data for a $1 \mu \mathrm{m}$ thick $\mu c$-Si:H solar cell in comparison with simulated quantum efficiencies for idealized material properties by Vanecek et al., the calculated absorbance limit of silicon in air based on the model by Tiedje et al. [Eq. (2)], and double pass absorption assuming no light trapping but ideal reflectivity at the back contact $\left(A_{\text {noLT }}=1-\exp [-2 \alpha d]\right)$. For convenience, we take $4 n^{2}$ to be a constant equal to 50 in the wavelength range of interest.

In order to compare the light-trapping ability, cell current densities of the spectral region from 650 to $1100 \mathrm{~nm}$ [labels in Fig. 14(a)] and the effective light pass enhancement factor $f$ were calculated [Fig. 14(b)]. Table I gives an overview of
TABLE I. Comparison of quantum efficiencies and absorbencies at $\lambda$ $=0.9 \mu \mathrm{m}$ (center column) and calculated cell current densities in the spectral region of $650-1100 \mathrm{~nm}$ (right column). The values correspond to the data shown in Fig. 14. Additional experimental data of $\mu c-\mathrm{Si}: \mathrm{H}$ solar cell with $i$-layer thickness of $1 \mu \mathrm{m}$ and TAC of $1 \mathrm{wt} \%$ are shown as well (same data as in Fig. 12).

\begin{tabular}{lcc}
\hline \hline & $\begin{array}{c}\text { QE, } A(\%) \\
\text { at } \lambda=0.9 \mu \mathrm{m}\end{array}$ & $\begin{array}{c}\text { Cell current density } \\
\left(\mathrm{mA} / \mathrm{cm}^{2}\right) \\
\text { at } 650-1100 \mathrm{~nm}\end{array}$ \\
\hline No light trapping $A_{\text {noLT }}$ & 5 & 4.8 \\
Experimental QE, TAC $=1 \mathrm{wt} \%$ & 26 & 10.5 \\
Experimental QE, TAC $=0.5 \mathrm{wt} \%$ & 32 & 11.7 \\
QE simulation, Vanecek et al. & 39 & 14.0 \\
Absorbance limit, $A_{\mathrm{LT}}$, Tiedje et al. & 57 & 16.8 \\
\hline \hline
\end{tabular}

the data shown in Fig. 14. Experimentally determined quantum efficiency at $\lambda=0.9 \mu \mathrm{m}$ and calculated cell current density generated in the spectral region from 650 to $1100 \mathrm{~nm}$ of $\mu c$-Si:H solar cells with intrinsic silicon absorber thickness of $1 \mu \mathrm{m}$ are given for front contact $\mathrm{ZnO}$ :Al with TACs of 0.5 and $1 \mathrm{wt} \%$ (shown in Fig. 12). These values are compared to calculated absorbencies $A_{\text {noLT }}$ and $A_{\mathrm{LT}}$, as well as simulated quantum efficiency from Vanecek et al. ${ }^{48}$ Without any light trapping the effective light pass enhancement factor is limited by $f=2$ [compare Fig. 14(b)] due to a single ideal reflection at the back contact. A current density of $4.8 \mathrm{~mA} / \mathrm{cm}^{2}$ is generated in the spectral region from 650 to $1100 \mathrm{~nm}$. The experimentally studied cell generates $11.7 \mathrm{~mA} / \mathrm{cm}^{2}$ in this spectral region and shows enhancement factors of up to 16 . These values can be increased further. If a cell with reduced parasitic absorption losses amounting to one-third of the experimental status at the time of the publication by Vanecek et al. is assumed, then simulations predict $14.0 \mathrm{~mA} / \mathrm{cm}^{2}$ and $f \leqslant 19$ (derived from data by Vanecek et al. in the spectral region from 650 to $1100 \mathrm{~nm}$ ). The statistical mechanical limit is given by the absorbance calculated by Tiedje et al. Here, we find $f$ values approaching the Yablonovitch limit of 50 with increasing wavelength (decreasing absorption coefficient). In our experiment and in the simulation by Vanecek et al. the highest $f$ values are found in the spectral region from 900 to $950 \mathrm{~nm}$. In this spectral region the limit of Tiedje et al. shows $f$ values of 32-38. Even though the solar spectrum itself limits the cell current density in the spectral region of $650-1100 \mathrm{~nm}$ to about $27 \mathrm{~mA} / \mathrm{cm}^{2}$, the model by Tiedje et al. predicts a significantly lower possible contribution to the cell current density of only $16.8 \mathrm{~mA} / \mathrm{cm}^{2}$. As long as Lambertian scattering is considered, this limit cannot be surpassed simply due to the vanishing absorption coefficient of $\mu c-\mathrm{Si}: \mathrm{H}$ material, which leads to a significant amount of light escaping from the device.

\section{B. Further potential for improvement}

Calculations shown in Fig. 14 and in Table I predict a potential gain in cell current density of $5.1 \mathrm{~mA} / \mathrm{cm}^{2}$ in the spectral range of 650-1100 $\mathrm{nm}$ if we compare our experimental results with calculated limits based on the work of Tiedje et al. An increase of $1 \mathrm{~mA} / \mathrm{cm}^{2}$ can easily be achieved by using an antireflection coating at the glass side 


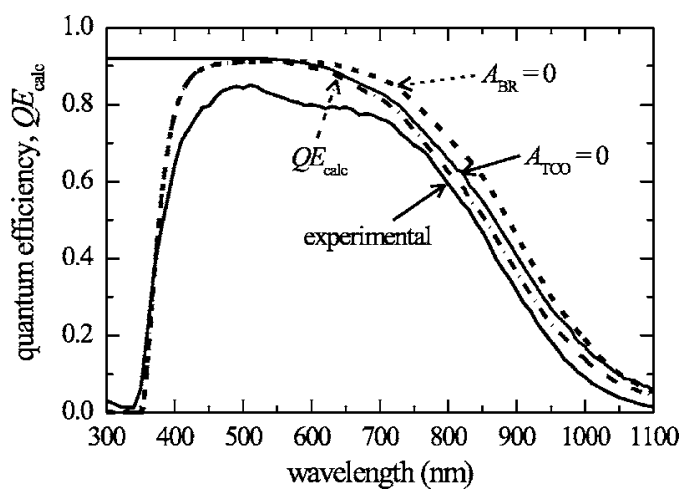

FIG. 15. Measured quantum efficiency [same data as shown in Figs. 12 and 14(a)] and $\mathrm{QE}_{\text {calc }}$ for single junction $\mu c-\mathrm{Si}: \mathrm{H}$ solar cells with intrinsic layer thickness of $1 \mu \mathrm{m}$ and front contact with $0.5 \mathrm{wt} \%$ TAC. Additionally, calculations employing $A_{\mathrm{TCO}}=0$ and $A_{\mathrm{BR}}=0$ are also shown.

of the solar cell and between the glass and front contact TCOs. By significantly optimizing the optical properties of the whole solar cell device to the nearly idealized level considered in the simulation of Vanecek et al., it would be possible to gain up to $2.3 \mathrm{~mA} / \mathrm{cm}^{2}$ cell current density in the spectral range of $650-1100 \mathrm{~nm}$. These values show that our experimentally achieved light trapping is already very good. In Figs. 11 and 12, we show experimentally the significance of a reduced parasitic front contact $\mathrm{ZnO}: \mathrm{Al}$ absorption $A_{\mathrm{TCO}}$. An increase in cell current density was achieved by reducing TAC from 2 and $1 \mathrm{wt} \%$ to $0.5 \mathrm{wt} \%$. A decrease in TAC of the front contact to $0.2 \mathrm{wt} \%$ did not significantly increase cell current densities any further (compare Fig. 11). The parasitic absorptions in the doped silicon layers and at the back reflector were not affected in this study. Thus, we want to estimate whether parasitic absorption in the front contact or in the back reflector is the dominant factor in the case of front contacts with $0.5 \mathrm{wt} \%$ TAC. For this purpose, the work by Deckman et al. can be applied. Deckman et al. calculated a theoretical absorption probability $F^{\mathrm{enh}}$ using an infinite geometric progression. ${ }^{49}$ Internal randomization and Lambertian light scattering are assumed. The calculation considers the sum of parasitic absorptions in the front contact $A_{\mathrm{TCO}}$ and at the back reflector $A_{\mathrm{BR}}$ and the absorption coefficient $\alpha$, refractive index $n$, and thickness $d$ of silicon. Multiple reflections lead to an absorption in the silicon given by ${ }^{49}$

$$
F^{\mathrm{enh}}=\frac{1-\left(A_{\mathrm{TCO}}+A_{\mathrm{BR}}\right) e^{-2 \alpha d}-\left(1-A_{\mathrm{TCO}}-A_{\mathrm{BR}}\right) e^{-4 \alpha d}}{1-\left(1-A_{\mathrm{TCO}}-A_{\mathrm{BR}}\right) e^{-4 \alpha d}+\left(1-A_{\mathrm{TCO}}-A_{\mathrm{BR}}\right) n^{-2} e^{-4 \alpha d}} .
$$

In order to compare calculations based on this formula with measured quantum efficiencies, we consider reflection losses $R_{\text {front }}$ at the air/glass, glass/front contact, and front contact/ silicon interfaces and absorption losses in the front contact before entering the silicon for the first time. The calculated quantum efficiency $\mathrm{QE}_{\text {calc }}$ based on $F^{\mathrm{enh}}$ of Deckman et al. is then given by

$$
\mathrm{QE}_{\text {calc }}=F^{\mathrm{enh}}\left(1-R_{\text {front }}-A_{\mathrm{TCO}}\right) .
$$

$R_{\text {front }}$ is assumed to be $8 \%$ throughout the spectral range under consideration. In Fig. 15 we compare the measurements with calculations based on Eq. (4). A $\mu c-\mathrm{Si}: \mathrm{H}$ single junc-
TABLE II. Comparison of quantum efficiencies at $\lambda=0.9 \mu \mathrm{m}$ and calculated cell current densities in the spectral region of $650-1100 \mathrm{~nm}$ for single junction $\mu c$-Si:H solar cells with $i$-layer thickness of $1 \mu \mathrm{m}$. The values shown in the left-hand columns correspond to the data shown in Fig. 15 for front contact $\mathrm{ZnO}: \mathrm{Al}$ with $\mathrm{TAC}$ of $0.5 \mathrm{wt} \%$. The right-hand columns give corresponding calculation results for front contact $\mathrm{ZnO}$ :Al with TAC of $1 \mathrm{wt} \%$.

\begin{tabular}{lccccc}
\hline \hline & \multicolumn{2}{c}{$\mathrm{TAC}=0.5 \mathrm{wt} \%$} & & \multicolumn{2}{c}{ TAC $=1 \mathrm{wt} \%$} \\
\cline { 2 - 3 } \cline { 5 - 6 } & & $\begin{array}{c}\text { Cell current } \\
\text { density } \\
\left(\mathrm{mA} / \mathrm{cm}^{2}\right)\end{array}$ & & & $\begin{array}{c}\text { Cell current } \\
\text { density } \\
\left(\mathrm{mA} / \mathrm{cm}^{2}\right)\end{array}$ \\
\hline Experimental & 32 & 11.7 & & 26 & 10.5 \\
Calculation & 36 & 12.9 & & 31 & 11.9 \\
Calculation with $A_{\mathrm{TCO}}=0$ & 41 & 13.6 & & 41 & 13.6 \\
Calculation with $A_{\mathrm{BR}}=0$ & 46 & 14.6 & & 38 & 13.3 \\
\hline \hline
\end{tabular}

tion cell with $1 \mu \mathrm{m}$ intrinsic silicon thickness and front contact $\mathrm{ZnO}: \mathrm{Al}$ with $\mathrm{TAC}$ of $0.5 \mathrm{wt} \%$ was considered. While front contact absorptions $A_{\text {TCO }}$ were determined using photothermal deflection spectroscopy, back reflector absorption $A_{\mathrm{BR}}$ was calculated using spectrometer reflectivity measurements of a smooth $\mathrm{ZnO} / \mathrm{Ag}$ back reflector. This will underestimate the influence of absorption losses at the back reflector, since rough $\mathrm{ZnO} / \mathrm{Ag}$ layers used in solar cells show higher parasitic absorptions. ${ }^{43,44}$ In Table II quantum efficiencies at $\lambda=0.9 \mu \mathrm{m}$ and cell current densities in the spectral region of 650-1100 nm are given for front contact TACs of 0.5 and $1 \mathrm{wt} \%$. Even though the calculation based on Eq. (4) does not incorporate parasitic absorption losses in doped silicon layers and electrical collection efficiency losses, the calculated values $\mathrm{QE}_{\text {calc }}$ approximate the experimental data very well, especially in the wavelength range of $750-950 \mathrm{~nm}$. We thus studied the potential of further improvements for reducing parasitic losses by employing formula (3) from Deckman et al. We considered the case of a front contact without parasitic losses $\left(A_{\mathrm{TCO}}=0\right)$ as well as a back reflector without parasitic losses $\left(A_{\mathrm{BR}}=0\right)$. Figure 15 shows the results for a TAC of $0.5 \mathrm{wt} \%$ and Table II gives the quantum efficiency values at $\lambda=0.9 \mu \mathrm{m}$ and cell current densities for the spectral range of $650-1100 \mathrm{~nm}$ for both TACs of 0.5 and $1 \mathrm{wt} \%$. Comparing the different amounts of parasitic front contact absorptions using TAC of $0.5 \mathrm{wt} \%$ instead of $1 \mathrm{wt} \%$, a current density increase in the spectral range of $650-1100 \mathrm{~nm}$ of $1.0 \mathrm{~mA} / \mathrm{cm}^{2}$ can be found based on the calculated $\mathrm{QE}_{\text {calc }}\left(1.2 \mathrm{~mA} / \mathrm{cm}^{2}\right.$ in the experiment). If a front contact with TAC of $0.5 \mathrm{wt} \%$ is used, there is only a further potential of up to a $0.7 \mathrm{~mA} / \mathrm{cm}^{2}$ increase in cell current density $(650-1100 \mathrm{~nm})$ by neglecting the parasitic front contact absorption, whereas a reduction in parasitic back reflector absorption offers an increase in cell current density $(650-1100 \mathrm{~nm})$ of up to $1.7 \mathrm{~mA} / \mathrm{cm}^{2}$. In the case of front contacts with TAC of $1 \mathrm{wt} \%$, a potential increase in cell current density of up to $1.7 \mathrm{~mA} / \mathrm{cm}^{2}$ and up to $1.4 \mathrm{~mA} / \mathrm{cm}^{2}$ $(650-1100 \mathrm{~nm})$ can be expected in the case of lower front contact and back reflector absorption, respectively. Thus, we conclude that in the case of front contacts with $1 \mathrm{wt} \% \mathrm{TAC}$, the parasitic absorption in these front contacts substantially 
limits the quantum efficiency, while in the case of front contacts with $0.5 \mathrm{wt} \%$ TAC parasitic absorptions of the back reflector dominate. This can explain the very similar cell current densities found in the case of TACs of 0.5 and 0.2 wt \% (compare Fig. 11). Thus, further improvements have to focus on decreasing the parasitic absorption of the back reflector. In order to increase light trapping beyond the limit of Yablonovitch et al. consideration must be given to systems that are not covered by their theoretical approach. The application of photonic crystals might offer considerable potential since such a system is nonergodic. ${ }^{50,51}$ It should be noted that this discussion focuses merely on the long wavelength range. The blue response is limited by the TCO and $p$-type silicon absorption.

\section{CONCLUSIONS}

We investigated the influence of the doping level of the sputter target and the substrate temperature on the postetching surface texture of $\mathrm{ZnO}: \mathrm{Al}$ films and their light-trapping ability in silicon thin-film solar cells. Depending on the target alumina concentration (TAC) and substrate temperature, three different postetching surface topography types were found. At low TAC and low substrate temperatures during sputtering, the postetching surface topography typically comprises a rough surface with small lateral feature sizes (about $300 \mathrm{~nm}$ ) and relatively steep edges. At high TAC and high substrate temperatures, after etching we find a rather flat surface with plenty of shallow craters with depths of up to about $100 \mathrm{~nm}$ and a few large craters with lateral diameters of up to about $3 \mu \mathrm{m}$ and depths limited by film thickness. Between these two parameter regimes, postetching surface topographies are found almost uniformly covered by craters of approximately the same sizes (diameters of about $1-3 \mu \mathrm{m}$ and depths of about $150-400 \mathrm{~nm}$ ).

We find a significant influence of TAC on film growth. In order to incorporate these findings into the modified Thornton model introduced by Kluth et al., ${ }^{30}$ the substrate temperature axis is rescaled with respect to TAC since increasing substrate temperature and increasing TAC both have similar effects on growth conditions.

Based on the results presented here, we propose the following guidelines for the preparation of optimized front contact $\mathrm{ZnO}$ :Al films for use in thin-film silicon solar cells. A target with a TAC in the range of $0.5-1 \mathrm{wt} \%$ allows a good compromise between electrical and optical needs. Substrate temperatures in a certain temperature range $\left(360-410^{\circ} \mathrm{C}\right.$ for the recommended TAC) and low sputter pressures (typically $\leqslant 0.3 \mathrm{~Pa}$ ) enable sputtering of $\mathrm{ZnO}$ :Al films with high mobility (up to $49 \mathrm{~cm}^{2} \mathrm{~V}^{-1} \mathrm{~s}^{-1}$ ) and high crystal quality. The surface topography after etching in $\mathrm{HCl}$ shows high haze values of up to $40 \%$ at a wavelength of $1 \mu \mathrm{m}$, high rms roughness $>125 \mathrm{~nm}$, and crater opening angles between $120^{\circ}$ and $135^{\circ}$, which is suitable for efficient light trapping in silicon thin-film solar cells. Cell current densities of up to $26.8 \mathrm{~mA} / \mathrm{cm}^{2}$ have been achieved in a $\mu c-\mathrm{Si}: \mathrm{H}$ single junction cell with an absorber layer thickness of $1.9 \mu \mathrm{m}$.

Calculations of an effective light pass enhancement factor showed improvement of light trapping with increasing front contact transparency. Due to the multiple passes of light within the cell (light pass enhancement factors of up to 16), parasitic absorption within the $\mathrm{ZnO}: \mathrm{Al}$ front contact can limit further gains in cell current density. Nevertheless, an increase in cell current density in the spectral range important for light trapping in $\mu c-\mathrm{Si}: \mathrm{H}$ cells $(650-1100 \mathrm{~nm})$ from $4.8 \mathrm{~mA} / \mathrm{cm}^{2}$ (no light trapping) to $11.7 \mathrm{~mA} / \mathrm{cm}^{2}$ has been realized with an optimized front TCO. A comparison was made of the current experimental status with theoretical limitations for ideal light trapping and simulation results presented in the literature. We find that the $\mathrm{ZnO}$ :Al films developed in this study are almost fully optimized and further improvements require a reduction of parasitic absorption losses at the back reflector.

\section{ACKNOWLEDGMENTS}

The authors would like to thank A. Doumit, J. Kirchhoff, J. Klomfaß, W. Reetz, H. Siekmann, and B. Zwaygardt for technical assistance, R. Carius and C. Das for helpful discussions, and $\mathrm{S}$. Jorke for contributions to AFM data analysis. They also thank H.P. Bochem at the Institute of Bio- and Nanosystems for SEM measurements. They gratefully acknowledge financial support from the Bundesministerium für Umwelt, Naturschutz und Reaktorsicherheit (German Federal Ministry for the Environment, Nature Conservation and Nuclear Safety) (Contract No. 0329923 A) and the European Commission (Athlet project, Contract No. 019670).

${ }^{1}$ A. Goetzberger, C. Hebling, and H. W. Schock, Mater. Sci. Eng., R. 40, 1 (2003).

${ }^{2}$ R. W. Miles, Vacuum 80, 1090 (2006).

${ }^{3}$ J. P. Benner and L. Kazmerski, IEEE Spectrum 36, 34 (1999).

${ }^{4}$ P. D. Maycock, Refocus 6, 18 (2005).

${ }^{5}$ S. Hegedus, Prog. Photovoltaics 14, 393 (2006).

${ }^{6}$ M. A. Green, Prog. Photovoltaics 14, 383 (2006)

${ }^{7}$ K. L. Chopra, P. D. Paulson, and V. Dutta, Prog. Photovoltaics 12, 69 (2004).

${ }^{8}$ M. S. Keshner and R. R. Arya, Proceedings of the 15 th International Photovoltaic Science and Engineering Conference PVSEC, Shanghai, China (SSTP, Shanghai, 2005), p. 149.

${ }^{9}$ D. L. Staebler and C. R. Wronski, Appl. Phys. Lett. 31, 292 (1977).

${ }^{10}$ M. Stutzmann, W. B. Jackson, and C. C. Tsai, Phys. Rev. B 32, 23 (1985).

${ }^{11}$ Y. Uchida, M. Nishiura, H. Sakai, and H. Haruki, Sol. Cells 9, 3 (1983).

${ }^{12}$ H. Sakai and Y. Ichikawa, J. Non-Cryst. Solids 137-138, 1155 (1991).

${ }^{13}$ J. Yang, A. Banerjee, and S. Guha, Sol. Energy Mater. Sol. Cells 78, 597 (2003).

${ }^{14} \mathrm{C}$. Wang and G. Lucovsky, Proceedings of the 21st IEEE Photovoltaic Specialists Conference, Kissimmee, Florida (IEEE, New York, 1990), p. 1614.

${ }^{15}$ J. Yang, B. Yan, and S. Guha, Thin Solid Films 487, 162 (2005).

${ }^{16}$ R. Flückiger, J. Meier, M. Goetz, and A. Shah, J. Appl. Phys. 77, 712 (1995).

${ }^{17}$ S. Klein, F. Finger, R. Carius, T. Dylla, B. Rech, M. Grimm, L. Houben, and M. Stutzmann, Thin Solid Films 430, 202 (2003).

${ }^{18}$ J. Meier, S. Dubail, R. Flückiger, D. Fischer, H. Keppner, and A. Shah, Proceedings of the IEEE First World Conference on Photovoltaic Solar Energy Conversion (WCPEC), Waikoloa, Hawaii (IEEE, New York, 1994), p. 409.

${ }^{19}$ H. Keppner, J. Meier, P. Torres, D. Fischer, and A. Shah, Appl. Phys. A: Mater. Sci. Process. 69, 169 (1999).

${ }^{20}$ A. V. Shah et al., Prog. Photovoltaics 12, 113 (2004).

${ }^{21}$ B. Rech, T. Repmann, S. Wieder, M. Ruske, and U. Stephan, Thin Solid Films 502, 300 (2006).

${ }^{22}$ K. Yamamoto, Prog. Photovoltaics 13, 489 (2005).

${ }^{23}$ M. A. Green, K. Emery, D. L. King, Y. Hishikawa, and W. Warta, Prog. Photovoltaics 14, 455 (2006). 
${ }^{24}$ B. Rech and H. Wagner, Appl. Phys. A: Mater. Sci. Process. A69, 155 (1999).

${ }^{25}$ J. Müller, B. Rech, J. Springer, and M. Vanecek, Sol. Energy 77, 917 (2004).

${ }^{26}$ C. Agashe, O. Kluth, J. Hüpkes, U. Zastrow, and B. Rech, J. Appl. Phys. 95, 1911 (2004).

${ }^{27}$ O. Kluth et al., Thin Solid Films 351, 247 (1999).

${ }^{28}$ B. Rech et al., Thin Solid Films 511-512, 548 (2006).

${ }^{29}$ F. C. M. van de Pol, F. R. Blom, and Th. J. A. Popma, Thin Solid Films 204, 349 (1991).

${ }^{30}$ O. Kluth, G. Schöpe, J. Hüpkes, C. Agashe, J. Müller, and B. Rech, Thin Solid Films 442, 80 (2003).

${ }^{31}$ J. Müller, G. Schöpe, B. Rech, H. Schade, P. Lechner, R. Geyer, H. Stiebig, and W. Reetz, Proceedings of the Third WCPEC, Osaka, Japan (IEEE, New York, 2003), Vol. B, p. 1839.

${ }^{32}$ J. Hüpkes, B. Rech, S. Calnan, O. Kluth, U. Zastrow, H. Siekmann, and M. Wuttig, Thin Solid Films 502, 286 (2006).

${ }^{33}$ O. Kluth, G. Schöpe, B. Rech, R. Menner, M. Oertel, K. Orgassa, and H. W. Schock, Thin Solid Films 502, 311 (2006).

${ }^{34}$ Y. Gotoh, A. Adachi, and M. Mizuhashi, Reports Research Lab. Asahi Glass Co., Ltd. 37, 13 (1987).

${ }^{35}$ B. Rech, T. Roschek, T. Repmann, J. Müller, R. Schmitz, and W. Appenzeller, Thin Solid Films 427, 157 (2003).

${ }^{36}$ N. Fujimura, T. Nishihara, S. Goto, J. Xu, and T. Ito, J. Cryst. Growth 130, 269 (1993).

${ }^{37}$ K. L. Chopra, S. Major, and D. K. Pandya, Thin Solid Films 102, 1
(1983).

${ }^{38}$ E. Burstein, Phys. Rev. 93, 632 (1954).

${ }^{39}$ T. S. Moss, Proc. Phys. Soc. London, Sect. B 67, 775 (1954).

${ }^{40}$ P. Lechner, R. Geyer, H. Schade, B. Rech, O. Kluth, and H. Stiebig, Proceedings of the 19th European PVSEC, Paris (WIP, Munich, 2004), p. 1591.

${ }^{41}$ H. Stiebig, M. Schulte, C. Zahren, C. Haase, B. Rech, and P. Lechner, Proc. SPIE 6197, 6197-01 (2006).

${ }^{42}$ R. Carius, Photovoltaic and Photoactive Materials-Properties, Technology and Applications (Kluwer Academic, Dordreeht, 2002), p. 93.

${ }^{43}$ J. Springer, A. Poruba, L. Müllerova, M. Vanecek, O. Kluth, and B. Rech, J. Appl. Phys. 95, 1427 (2004).

${ }^{44}$ J. Springer, A. Poruba, and M. Vanecek, J. Appl. Phys. 96, 5329 (2004).

${ }^{45}$ E. Yablonovitch and G. D. Cody, IEEE Trans. Electron Devices 29, 300 (1982).

${ }^{46}$ E. Yablonovitch, J. Opt. Soc. Am. 72, 899 (1982).

${ }^{47}$ T. Tiedje, E. Yablonovitch, G. D. Cody, and B. G. Brooks, IEEE Trans. Electron Devices 31, 711 (1984).

${ }^{48} \mathrm{M}$. Vanecek et al., Proceedings of the Third WCPEC, Osaka, Japan (IEEE, New York, 2003), Vol. B, p. 1527.

${ }^{49}$ H. W. Deckman, C. R. Wronski, H. Witzke, and E. Yablonovitch, Appl. Phys. Lett. 42, 968 (1983)

${ }^{50}$ E. Yablonovitch, J. Opt. Soc. Am. B 10, 283 (1993).

${ }^{51}$ J. M. Gee, Conference Record of the 29th IEEE PVSEC, New Orleans (IEEE, New York, 2002), p. 150. 